\title{
Microstructural Evolution And Mechanical Properties of FCAW Joints In 9\% Ni Steel Prepared With Two Types of Ni-Based Weld Metals
}

\author{
Jiyong Hwang \\ Korea Institute of Industrial Technology \\ Kwangsu Choi \\ Korea Institute of Industrial Technology

\section{Sang Min Lee} \\ Korea Institute for Defense Analyses \\ Hyo Yun Jung ( $\nabla$ hjung@kitech.re.kr) \\ Korea Institute of Industrial Technology
}

\section{Research Article}

Keywords: 9\% Ni steel, flux-cored arc welding, microstructure evolution, transition area, low-temperature toughness

Posted Date: January 7th, 2022

DOI: https://doi.org/10.21203/rs.3.rs-1218593/v1

License: (9) This work is licensed under a Creative Commons Attribution 4.0 International License. Read Full License

Version of Record: A version of this preprint was published at The International Journal of Advanced Manufacturing Technology on April 18th, 2022. See the published version at https://doi.org/10.1007/s00170-022-09173-5. 


\section{Abstract}

The microstructural and mechanical evaluation of $9 \% \mathrm{Ni}$ steel with Flux-Cored Arc Welding was performed with two different Nibased weld metals: Inconel 625 and Hastelloy 609. Weld metals showed the microstructural change depending on the temperature gradient and crystal growth rate for each region during the cooling after welding. At the bottom of the weld metal, which is rapidly cooled in contact with the cold base metal, a cellular/planar growth was exhibited due to a large temperature gradient and low crystal growth rate. While, columnar dendrites were exhibited in the central region cooled relatively slowly and precipitates were observed in the interdendritic region. In the low-temperature toughness test, the absorbed impact energies were 89 and $55 \mathrm{~J}$ for Inconel 625 and Hastelloy 609 , respectively. When Inconel 625 is used as the weld metal compared to Hastelloy 609 , the high content of the $Y$ stabilizer and martensite start temperature decreasing elements leads to the formation of a thicker $y$-phase layer and thinner martensite layer in the transition region. In addition, high content of these elements suppresses the martensite transformation and maintains the stability of the weld joint interface even at low temperatures, resulting in the higher absorbed impact energy.

\section{Introduction}

In 2020, the International Maritime Organization (IMO) imposed a new upper limit of $0.5 \%$ sulfur content in the shipping fuel (reduced from 3.5\%) [1]. The new regulation aims to reduce the harmful sulfur oxide emissions from ships and prompts the shipping industry to adopt environmentally friendly fuels. Liquefied natural gas (LNG), a well-established low-sulfur alternative to petroleum, is drawing attention as a next-generation clean fuel because it significantly reduces the emission of air pollutants such as sulfur oxide, nitrogen oxide, carbon dioxide, and soot [2].

The LNG-fueled ships require cryogenic fuel tanks suitable for the long-term storage of LNG at temperatures below its liquefaction temperature of $-162^{\circ} \mathrm{C}$. One of the most widely used materials for the construction of such cryogenic storage tanks is $9 \% \mathrm{Ni}$ steel, owing to its good tensile strength and excellent impact toughness, which makes it highly suitable for cryogenic applications $[3,4]$. Nibased superalloys such as Inconel ${ }^{\circledR}$ and Hastelloy ${ }^{\circledR}$ are used as welding materials for this steel, and mainly comprise an austenite phase, resulting in good crack resistance and excellent low-temperature fracture toughness [4,5]. These properties make them highly suitable for welding $9 \% \mathrm{Ni}$ steel. However, in the weld joint between dissimilar metals (Fe-based base material and Ni-based superalloys), a dilution area is created where the material microstructure and properties change. This dilution phenomenon plays a crucial role in determining the toughness of the cryogenic storage tanks made by $9 \% \mathrm{Ni}$ steel $[6,7]$.

It is important to understand the weld-joint properties of $9 \% \mathrm{Ni}$ steel with Ni-based superalloys, and their increasing use in manufacturing cryogenic LNG storage tanks requires a more in-depth examination of the mechanical and structural properties of the Ni-based weld joints to ensure an improved low-temperature toughness. The conventional welding methods such as shielded metal arc welding (SMAW) and submerged arc welding (SAW) have been widely used for $9 \% \mathrm{Ni}$ steel and Ni-based weld metal welding $[4,5$, 8-10]. Moreover, flux-cored arc welding (FCAW) is expected to have a good efficiency and adaptability for welding $9 \%$ Ni steel, but the microstructure and properties of the FCAW joint remain to be explored.

In this study, the Ni-based superalloys, Inconel ${ }^{\circledR}$ and Hastelloy ${ }^{\circledR}$, were used as welding metals for $9 \% \mathrm{Ni}$ steel. The microstructure and low-temperature toughness of the welding area were systematically examined depending on the type of Ni-based weld metal used for the FCAW of the $9 \% \mathrm{Ni}$ steel base metal. For this, a metallographic analysis of the microstructure was performed in each of the joint interfaces formed by single beads of Hastelloy 609 and Inconel 625 weld metal, which were welded under identical conditions.

\section{Experimental Methods}

The chemical composition of the base metal and weld metals was investigated using the inductively coupled plasma (ICP, Perkin Elmer, Optima 7300DV, USA) analysis. The composition of the $9 \% \mathrm{Ni}$ steel (Nippon steel \& Sumitomo metal corporation) and Nibased weld metals are listed in Table 1 and Table 2, respectively. Flux-cored wire (FCW) with a diameter of $1.2 \mathrm{~mm}$ was the weld metal. The welding was carried out in a single pass using FCAW for each of the weld metals. The welding conditions are summarized in Table 3. The same welding conditions were used for all the specimens, whereas different weld metal samples were used each time. The microstructure of the weld joint was analyzed using optical microscopy (OM, Hirox, MXB-5000REZ, Japan) and field emission-scanning electron microscopy (FE-SEM, Hitachi, SU8230, Japan) equipped with an electron backscatter diffraction (EBSD, 
Oxford, Aztec HKL Nordlys Nano, United Kingdom) equipment. Compositional analysis of the weld joint was performed through point and line measurements using energy-dispersive spectrometry (EDS, Oxford, Ultim Max100, United Kingdom). For the crystal structure analysis, X-ray diffraction (XRD, Panalytical, EMPYREAN, United Kingdom) was performed within a $2 \theta$ scan range of $20-100^{\circ}$ with Cu-Ka radiation $(\lambda=1.54056 \AA)$. The scan speed was $3 \%$ min scaling with a step size of $0.02^{\circ}$. The beam size was $7 \mathrm{~mm} 1 / 2$ degree. A multi-layer FCAW process was performed to evaluate the low-temperature impact toughness of $9 \% \mathrm{Ni}$ steel with different weld metals. The multi-layer welded sample had a V-type notch with a $2 \mathrm{~mm}$ depth in the weld metal region. Charpy impact tests were performed for the weld metal area in a cryogenic environment at $-196^{\circ} \mathrm{C}$.

\section{Results}

Fig. 1 shows the XRD pattern of the base metal, weld metals, and weld-joint fabricated using FCAW of 9\% Ni steel with Hastelloy 609 and Inconel 625. The base metal shows the diffraction peaks of martensite and austenite-y phases (Fig. 1a). However, the weld metal as well as the weld-joint of the base metal and weld metal mainly show diffraction peaks of the austenite-y phases. The austenite peaks for Hastelloy 609 and its joint interface (Fig. 1c and 1e) appear at a lower scattering angle compared to those of the sample welded with Inconel 625 (Fig. 1b and 1d). The most likely reason for the peak shift is the difference in the solid-solution content of the minor element.

Fig. 2 shows the cross-sectional OM and SEM images of the joints welded with Hastelloy 609 and Inconel 625, respectively. With Fig. 2a and Fig. 2d, it is noted that the two weld joints are composed with clearly distinguishable weld metal, joint interface, and the heat-affected zone (HAZ) of the base metal. The center of the Hastelloy 609 bead comprises of columnar dendrites elongated upward, while the bottom of the bead exhibits dendrite-to-cellular transition morphologies (Fig. 2b and Fig. 2c). Precipitates of various sizes and shapes are located at the interdendritic regions. Similar precipitates were also observed at the bottom of the bead. In addition, the number of precipitates decreased toward the bottom of the bead. EDS was performed to investigate the compositional distribution in the weld metal, and the results are presented in Table 4. The Mo content in the interdendritic regions is higher than that in the dendritic regions, indicating that Mo tends to be rejected to an interdendritic residual liquid. Moreover, the interdendritic precipitates have high contents of W, indicating a high W solubility. These results imply that the solidification of the molten Hastelloy 609 starts in the y phase, while the $\sigma$ and $\rho$ phases start to form at later stages. In this case, the low Cr content of Hastelloy 609 stabilizes the $\rho$ phase rather than the $\sigma$ phase $[11,12]$. The precipitates located at the interdendritic regions are inferred to be in the $\rho$ phase based on the compositional analysis of Cieslak [12] and Qiu [11]. The $\mu$ phase, which results from the long-term phase transformation of the $\rho$ phase, is not present as heat was not applied for a sufficiently long time during FCAW [12].

The SEM images of the Inconel 625 bead reveal columnar-dendritic growth from most areas of the center of the bead till the bottom (Fig. 2e). Dendrite-to-cellular transition morphologies appear in some areas near the weld joint interface, as shown in Fig. $2 \mathrm{f}$. Moreover, similar to Hastelloy 609, precipitates are observed in the interdendritic regions. The compositional analysis reveals that the interdendritic regions are relatively rich in $\mathrm{Mo}$ and $\mathrm{Nb}$ (Table 4). These results suggest the liquid segregation of $\mathrm{Mo}$ and $\mathrm{Nb}$ during the weld joint solidification $[8,13]$. The compositional analysis of the interdendritic precipitates reveals that the Nb-enriched phase is $\mathrm{NbC}$. It has been established that the Inconel 625 alloy solidifies to the $y$ phase, $\mathrm{M} 6 \mathrm{C}$, and $\mathrm{Nb}$-rich phase ( $\mathrm{NbC}$, Laves) from its liquid state through the following process: $L \rightarrow L+Y \rightarrow L+Y+N b C \rightarrow L+Y+N b C+M 6 C \rightarrow L+Y+N b C+M 6 C+L a v e s \rightarrow Y+N b C+M 6 C+$ Laves [13-15]. The secondary phase $(\mathrm{NbC})$ has a high $\mathrm{Nb}$ content and can be distinguished from the Laves phase. However, it was difficult to identify the Laves phase and M6C even through magnified observations in this study. It was envisaged that a more detailed sample analysis in the future might be able to overcome this limitation.

The SEM images of the joint interface welded with Hastelloy 609, together with the EDS line analysis and EBSD images of the interface area, are presented in Fig. 3. In this case, elements with less than $1 \mathrm{wt}$. \% content are excluded from the analysis since such low values are considered to be below the accuracy limit of the EDS measurement. Compositional analysis was performed along a straight line over the joint interface, as shown in Fig. 3a. The results from the corresponding compositional analysis, shown in Fig. 3b, reveal a transition area in the Hastelloy 609 sample near the joint interface, where the elemental composition changes linearly in the direction of the weld metal. This transition area has a thickness of approximately $20 \mu \mathrm{m}$, where the Fe content decreases rapidly, while the $\mathrm{Ni}, \mathrm{Cr}, \mathrm{Mo}$, and $\mathrm{W}$ contents increase. An area farther away from the interface (region 3 in Fig. 3a) exhibits $20 \mathrm{wt}$ \% Fe, indicating a considerably wide dilution area. The transition area consists of a uniform martensite layer (region 1 in Fig. 3c and 3d) and a y-phase-planar growth area (region 2 in Fig. 3c and 3d). 
The SEM image of the Inconel 625 joint interface (Fig. 4) reveals a similar structure to that of the Hastelloy 609 joint interface (Fig. 4a). The transition area near the interface is $33 \mu \mathrm{m}$ thick. Within the transition area, the Fe content decreases when scanning in the direction from the base metal toward the weld metal, while the $\mathrm{Ni}, \mathrm{Cr}, \mathrm{Mo}$, and $\mathrm{Nb}$ contents increase simultaneously (Fig. 4b). A high $\mathrm{Nb}$ content is detected in the interdendritic precipitates, confirming the presence of an $\mathrm{NbC}$ phase. In Fig. $4 \mathrm{c}$ and $4 \mathrm{~d}$, two layers can be distinguished within the transition: the martensite layer (region 1 in Fig. 4c and 4d) and the $\mathrm{y}$-phase-cellular growth area (region 2 in Fig. 4c and 4d).

To assess the toughness of the weld metals after welding, multilayer welding specimens, prepared from the same base metal and weld metal pairs, were subjected to low-temperature impact tests. The absorbed impact energies were higher than or equal to $55 \mathrm{~J}$ and $89 \mathrm{~J}$ for Hastelloy 609 and Inconel 625, respectively, as shown in Fig. 5. These values greatly exceed the impact absorption energy standards stipulated by the classification regulation (standard of Charpy impact energy: at $-196{ }^{\circ} \mathrm{C}, 27 \mathrm{~J}$ in the transverse direction and $41 \mathrm{~J}$ in the longitudinal direction).

\section{Discussion}

The microstructural analysis of the weld metal showed that the type of the dendritic growth varied depending on the position within the weld metal. The columnar dendrite structures in the central part of the weld bead exhibited well-defined secondary arms. At the bottom of the bead, the secondary dendritic arms nearly disappeared, and the morphology transitioned from dendritic to cellular. The temperature gradient and the crystal growth rate are the two main parameters that govern the microstructure of the weld joint during solidification. With the decrease of the temperature gradient and the increase of the growth rate, the microstructure transitions from planar through cellular, cellular-dendritic, and columnar-dendritic, to equiaxed dendritic [16]. The bottom of the weld bead that is in contact with the cold base metal cools more rapidly during the welding process, while the top of the bead cools slower. As a result, the planar or cellular growth predominantly occurs at the bottom of the bead. In contrast, in the center of the bead, the cooling is slower, which results in a lower temperature gradient and higher growth rate. Consequently, a columnar dendrite growth with distinctively developed secondary arms takes place in this part of the weld bead.

During welding, a dilution area is formed between the $9 \% \mathrm{Ni}$ steel and Ni-based weld metal, where both metals are mixed. The transition area of the joint interface where a compositional change occurs due to the dilution process consists of the martensite layer (region 1) and the y-phase-planar/cellular growth area (region 2). This microstructure of the transition area can be attributed to the temperature gradient and the elemental composition of the area. Since Ni is a y-phase stabilizing element, the Ni content in the base metal ( $9 \% \mathrm{Ni}$ steel) helps to stabilize the $\mathrm{y}$-phase at low temperatures. In the case of Hastelloy 609 , the $\mathrm{y}$-phase in region 2 with a $\mathrm{Ni}$ content of 20-45 wt. \% was preserved despite the Fe dilution. Additionally, planar growth morphology appeared in the same region due to the large temperature gradient and low growth rate induced by the rapid cooling from the cold base metal. In region 1, high Fe dilution of 60-90 wt. \% and low Ni content of 10-20 wt. \% were observed. Thereby, the martensite in the corresponding area became a relatively stable phase. Moreover, rapid cooling accelerates the martensite formation; hence, the presence of fine martensites indicate rapid cooling of the area. In the case of Inconel 625, the joint interface was also structured in two layers (region 1 and region 2). The factors that governed the growth morphology of the layers were the rapid cooling and the composition. The martensite layer was formed in areas with a high Fe and low $\mathrm{Ni}$ content, while the $\mathrm{y}$-phase-cellular morphology appeared in areas with a high $\mathrm{Ni}$ and low Fe content.

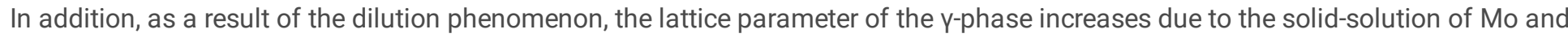
$\mathrm{Nb}$ atoms (with larger atomic radii than $\mathrm{Ni}$ and $\mathrm{Fe}$ ) in the $\mathrm{y}$-phase during welding (for reference, the atomic radii of $\mathrm{Ni}$, $\mathrm{Fe}, \mathrm{Mo}$, and $\mathrm{Nb}$ are $0.124,0.126,0.139$, and $0.146 \mathrm{~nm}$, respectively). This lattice expansion generates a low-angle shift of the $y$ peak in the XRD spectrum. The EDS data, summarized in Table 4, indicate that the Hastelloy 609 sample has a Mo content of approximately 10-16 wt. \%, while the Inconel 625 sample has $\mathrm{Mo}$ and $\mathrm{Nb}$ contents in the range of 7-10 wt. \%. Therefore, the y-phase peaks of Hastelloy 609 bead region and its joint interface appear at a lower diffraction angle because of the higher Mo solid-solution content. Moreover, the intensity of the $\gamma$-phase peak is higher at the weld joint interface compared to the peak intensity at the weld metal area, indicating an intense texture growth. The most likely reason for the strong $y$-phase peak is the aligned dendrite-to-cellular transition morphology that developed near the joint interface (or the bottom area of the weld metal bead) due to heat transfer. There is a deviation in the preferential growth direction for the joint interface areas by Hastelloy 609 and Inconel 625 . The low volume fraction of the $\mathrm{NbC}$ and $\rho$ phases prevents their reliable identification in the XRD pattern. 
There are microstructural changes that occur due to the cooling rate variations, by the position within the Hastelloy 609 and Inconel 625 beads, during the welding process. In both cases, aligned columnar dendrites were formed in the center of the bead, while the morphology changed from dendrite-cellular to cellular/planar growth toward the bottom of the bead. Moreover, precipitates were formed in the interdendritic regions of both the samples. The transition area of the weld joint was structured with two layers (martensite layer and y-phase cellular/planar layer) depending on the actual Fe and $\mathrm{Ni}$ content resulting from the dilution in the transition area. However, the microstructure of the transition area differs for the two weld metals. The use of Inconel 625 resulted in a transition area of $33 \mu \mathrm{m}$, compared to a $20 \mu \mathrm{m}$ thick transition area for Hastelloy 609, with an $8 \mu \mathrm{m}$ thick martensite layer. In contrast, the martensite layer for Hastelloy 609 was $11 \mu \mathrm{m}$ thick. Elements such as $\mathrm{Cr}$, Mo, and Ni lower the onset temperature for martensite transformation (martensite start temperature, Ms) in steel [6]. This implies an increase in the $y$-phase volume fraction and the inhibition of martensite formation. The high content of those elements in the transition area of Inconel 625 can explain the thick $\mathrm{y}^{-}$ phase layer and thin martensite layer observed in the transition.

This microstructure and the elemental composition of the transition area can influence the low-temperature fracture toughness. At low-temperatures, the difference in the thermal expansion coefficients between the Ni-based weld metal and the Fe-based base metal can cause cold shrinkage and mechanical stress at the joint interface. Such stresses can induce a transformation from austenite $\gamma^{-}$ phase to martensite in the joint transition area. In turn, the stress from the martensite transformation can augment the deformation in the adjacent $\mathrm{HAZ}$, and the residual deformation can lead to crack propagation $[6,17,18]$. Furthermore, the two materials commonly exhibited precipitation formation in the interdendritic regions upon microstructural analysis (the $\rho$ phase for 609 weld metal and NbC for 625 weld metal). Studies have reported that even a small number of interdendritic precipitations can induce intergranular crack propagation at low-temperatures, thus promoting brittle failure of the sample [8]. Additionally, the bond between the dendrite and the precipitate weakens due to the difference in the contraction rate between the $y$-phase and the precipitate, which deteriorates the lowtemperature fracture toughness. This crack propagation mechanism diagram is illustrated in Fig. 6 . However, the impact absorption energies of Hastelloy 609 and Inconel 625 were higher than the value suggested in the classification regulations. Further, the high content of the $\gamma$-stabilizing and Ms-decreasing elements present in Inconel 625 prevents martensite transformation. The $y$-phase stabilization process (martensite inhibition process) enhances the stability of the joint interface at low temperatures. In addition, in Inconel 625 , the initially thin martensite layer and thick y-phase layer that help to maintain the residual deformation at a low level increase its toughness. Consequently, a high low-temperature impact absorption energy of $89 \mathrm{~J}$, and an outstanding low-temperature toughness was observed when Inconel 625 was used.

Depending on the type of weld metal utilized, the difference in the dilution area extent and microstructure can be generated even under equal welding conditions. Furthermore, some microstructure types in the transition area along with the above-mentioned precipitation can negatively affect the fracture toughness. Therefore, in the future, a detailed discussion is necessary on the mechanical properties and microstructures dependent on weld metals and welding conditions.

\section{Conclusions}

The mechanical properties of the FCAW weld joints between 9\% Ni steel and Ni-based weld metals (Hastelloy 609 and Inconel 625) were investigated using the microstructure analysis. The findings of this study can be summarized in the following points:

- At the heterojunction between the $9 \% \mathrm{Ni}$ steel (Fe-based base metal) and Ni-based weld metals, a compositional transition area was created due to a dilution process at the joint interface. The transition areas for Hastelloy 609 and Inconel 625 were $20 \mu \mathrm{m}$ and $33 \mu \mathrm{m}$, respectively. Depending on the distribution of Fe and $\mathrm{Ni}$ in the transition area, two clearly distinguished layers were identified: the martensite layer, where the Fe content is relatively high, and the $y$-phase-cellular/planar layer, where the Ni content is high. The microstructure and compositional distribution at the welded part play an important role in determining the lowtemperature fracture toughness of the material. First, the observed precipitates in the interdendritic regions facilitate the intergranular crack propagation, thus adversely affecting the material toughness. In contrast, the high content of the $y$-stabilizing and Ms-decreasing elements impede martensite transformation, resulting in a relatively thick and stable y-phase layer. Thus, excellent toughness can be achieved by hindering additional martensite transformation and maintaining stability at the joint interface. These microstructures were found in the transition area with the application of Inconel 625, which is considered to have a higher toughness compared to Hastelloy 609.

- In the Hastelloy 609 weld joint, an $11 \mu \mathrm{m}$ martensite layer was observed, amounting to nearly half the thickness of the transition area. In contrast, despite having a thicker transition zone, the thickness of the martensite layer in the Inconel 625 weld joint was

Page 5/12 
approximately $1 / 4$ of the total thickness of the transition zone. In the Inconel 625 transition area, the high content of elements such as $\mathrm{Cr}$, Mo, and $\mathrm{Ni}$, which reduce the martensite transformation starting temperature of steel, inhibited the formation of martensite and increased the austenite volume fraction (thin martensite layer and thick y-phase layer).

- The variations in temperature gradients and crystal growth rates result from different cooling rates in various positions inside the bead. In the bead center, the relatively low temperature gradient and high growth rate result in directional columnar dendrite structures. Toward the bottom of the weld bead, where the temperature gradient is higher and the growth rate is lower, a transition from dendrite-cellular structures to cellular/planar morphologies was observed. Additionally, precipitates of the $\rho$ phase and $\mathrm{NbC}$ were found in the interdendritic regions of the Hastelloy 609 and Inconel 625 bead, respectively.

\section{Statements And Declarations}

\section{Funding}

This study has been conducted with the support of the Korea Institute of Industrial Technology as "Research project (kitech JA-210008)".

\section{Conflict of interest/Competing interests}

The authors have no conflicts of interest to declare that are relevant to the content of this article.

\section{Availability of data and material}

Not applicable

\section{Code availability}

Not applicable

\section{Ethics approval}

Not applicable

\section{Consent to participate}

The submission of the article has been approved by all co-authors

\section{Consent for publication}

The publication has been approved by all co-authors

\section{Authors' contributions}

Jiyong Hwang : data analysis, investigation, writing-original draft and revision

Kwangsu Choi : data collection and analysis

Sang Min Lee : review and comment

Hyo Yun Jung : supervision, review and editing

\section{References}

[1] IMO 2020 - cutting sulphur oxide emissions. International Maritime Organization. https://www.imo.org/en/MediaCentre/HotTopics/Pages/Sulphur-2020.aspx

[2] LNG: an energy of the future. elengy. https://www.elengy.com/en/lng/lng-an-energy-of-the-future.html 
[3] Du WS, Cao R, Yan YJ, Tian ZL, Peng Y, Chen JH (2008) Fracture behavior of 9\% nickel high-strength steel at various temperatures: part I. tensile tests. Mater Sci Eng A 486:611-625. https://doi.org/10.1016/j.msea.2007.09.057

[4] Kobelco (2011) Kobelco welding today. Kobe steel, LTD 14:1-12. https://www.kobelco.co.jp/ english/welding/files/kwt2011-02.pdf [5] John ND, John CL, Samuel DK (2009) Welding metallurgy and weldability of nickel-base alloys. 9\% Ni steels, 1 st edn. John Wiley \& Sons, Inc., New Jersey, pp 357

[6] Weidong M, Yan C, Min W, Xueming H (2020) Microstructure characteristics and properties of fusion boundary in 9\%Ni steel joint filled with Ni-based alloy. Mater Charact 165:110390. https://doi.org/10.1016/j.matchar.2020.110390

[7] Dupont JN, Kusko CS (2007) Martensite formation in austenitic/ferritic dissimilar alloy welds. Weld J 86:51s-54s.

[8] Weidong M, Yuzhang L, Yan C, Min W (2018) Cryogenic fracture toughness of 9\%Ni steel flux cored arc welds. J Mater Process Technol 252:804-812. https://doi.org/10.1016/j.jmatprotec. 2017.10.026

[9] Price AH (2013) Significant system parameters influencing HAZ properties in 9\%Ni steel. Sci Technol Weld join 6:255-260. https://doi.org/10.1179/136217101101538758

[10] Yoon YK, Kim JH, Shim KT (2012) Mechanical characteristics of 9\% Ni steel welded joint for LNG storage tank at cryogenic. Int J Mod Phys Conf Ser 06:355-360. https://doi.org/ 10.1142/S2010194512003431

[11] Zhijun Q, Bintao W, Hanliang Z, Zhiyang W, Alan H, Yan M, Huijun L, Ondrej M, David W (2020) Microstructure and mechanical properties of wire arc additively manufactured Hastelloy C276 alloy. Mater Des 195:109007.

https://doi.org/10.1016/j.matdes.2020.109007

[12] Cieslak MJ, Headley TJ, Romig AD (1986) The welding metallurgy of Hastelloy alloys C-4, C-22, and C-276. Metall Mater Trans A 17:2035-2047. https://doi.org/10.1007/BF02645001

[13] Camila PA, Francisco CAM, Luís FGS, Jorge CFJ, Leonardo SA, Matheus CM (2019) Performance of the Inconel 625 alloy weld overlay obtained by FCAW process. Rev Mater 24: https://doi.org/10.1590/S1517-707620190001.0627

[14] Cieslak MJ, Knorovsky GA, Headley TJ, Romig AD (1989) The solidification metallurgy of alloy 718 and other Nb-containing superalloys. Superalloys 718:59-68. https://doi.org/10.7449/1989/ SUPERALLOYS_1989

_59_68

[15] Camila PA, Soraia SS, Jorge CFJ, LuI's FGS, Leonardo SA, Matheus CM, Jean D (2020) Microstructural characterization of Inconel 625 nickel-based alloy weld cladding obtained by electroslag welding process. J Mater Eng Perform 29:3004-3015. https://doi.org/10.1007/s11665-020-04861-3

[16] Sindo K (2002) Welding metallurgy, 2nd edn. John Wiley \& Sons, Inc., New Jersey pp 155-166

[17] Fritz A, Jonathan DHP, Peter S, Michael O, Otmar K, Jozef P, Franz DF (2018) The effect of residual stresses and strain reversal on the fracture toughness of TiAl alloys. Mater Sci Eng A 709:17-29. https://doi.org/10.1016/j.msea.2017.10.010

[18] Tang J, Tieu AK, Jiang ZY (2006) Modelling of oxide scale surface roughness in hot metal forming. J Mater Process Technol 177:126-129. https://doi.org/10.1016/j.jmatprotec.2006.04.105

\section{Tables}

Table 1 Chemical composition of $9 \%$ Ni steel (wt. \%)

\begin{tabular}{|llllllll|}
\hline & $\mathrm{Fe}$ & $\mathrm{Ni}$ & $\mathrm{C}$ & $\mathrm{Si}$ & $\mathrm{Mn}$ & $\mathrm{P}$ & $\mathrm{S}$ \\
\hline $9 \% \mathrm{Ni}$ steel & Bal. & 8.860 & 0.060 & 0.250 & 0.600 & 0.007 & 0.001 \\
\hline
\end{tabular}

Page $7 / 12$ 
Table 2 Chemical composition of weld metals (wt. \%)

\begin{tabular}{|c|c|c|c|c|c|c|c|c|c|c|c|c|c|}
\hline $\begin{array}{l}\text { Weld } \\
\text { metal }\end{array}$ & $\mathrm{Ni}$ & $\mathrm{Cr}$ & Mo & $\mathrm{Nb}+\mathrm{Ta}$ & $\mathrm{Fe}$ & W & $\mathrm{Si}$ & $\mathrm{Mn}$ & $\mathrm{Ti}$ & C & $\mathrm{Cu}$ & $P$ & $S$ \\
\hline $\begin{array}{l}\text { Hastelloy } \\
609\end{array}$ & Bal. & 15.700 & 16.200 & & 6.600 & 3.300 & 0.270 & 0.270 & & 0.010 & & 0.012 & 0.002 \\
\hline \multicolumn{14}{|l|}{$\begin{array}{l}\text { (609 } \\
\text { weld } \\
\text { metal) }\end{array}$} \\
\hline $\begin{array}{l}\text { Inconel } \\
625\end{array}$ & Bal. & 21.600 & 8.600 & 3.570 & 1.800 & & 0.370 & 0.280 & 0.110 & 0.030 & 0.030 & 0.010 & 0.003 \\
\hline $\begin{array}{l}(625 \\
\text { weld } \\
\text { metal) }\end{array}$ & & & & & & & & & & & & & \\
\hline
\end{tabular}

Table 3 The welding conditions for $9 \% \mathrm{Ni}$ Steel and Ni-based weld metals

\begin{tabular}{|ll|}
\hline Welding parameters & \\
\hline Welding machine & CMT/KUKA \\
\hline Base metal & $9 \%$ Ni steel \\
\hline Weld metal (wire) & Ni-based alloy (Hastelloy 609, Inconel 625) \\
\hline Shield gas & Ar- $18 \% \mathrm{CO}_{2}$ \\
\hline Welding current $[\mathrm{A}]$ & 200 \\
\hline Welding speed $[\mathrm{cm} / \mathrm{min}]$ & 20 \\
\hline
\end{tabular}

Table 4 The results of EDS point analysis (wt. \%)

\begin{tabular}{|lllllllll|}
\hline Analysis region & & Phase & $\mathrm{Ni}$ & $\mathrm{Cr}$ & $\mathrm{Fe}$ & $\mathrm{Mo}$ & $\mathrm{Nb}$ & $\mathrm{W}$ \\
\hline Hastelloy 609 & Interdendrite & (Mo-rich) Y-phase & 48.28 & 15.21 & 18.52 & 15.64 & 2.36 \\
\cline { 2 - 8 } & Dendrite & Y-phase & 53.35 & 13.97 & 20.41 & 10.08 & 2.19 \\
\cline { 2 - 8 } & Precipitate & $\rho$-phase & 26.45 & 13.49 & 11.72 & 43.01 & 5.33 \\
\hline \multirow{2}{*}{ Inconel 625 } & Interdendrite & $($ Mo, Nb-rich) Y-phase & 59.99 & 21.70 & 8.75 & 7.12 & 2.44 & \\
\cline { 2 - 8 } & Dendrite & Y-phase & 61.46 & 21.42 & 9.51 & 6.22 & 1.39 \\
\cline { 2 - 8 } & precipitate & $\mathrm{NbC}$ & 10.34 & 7.87 & 2.30 & 4.77 & 74.73 \\
\hline
\end{tabular}

Figures 


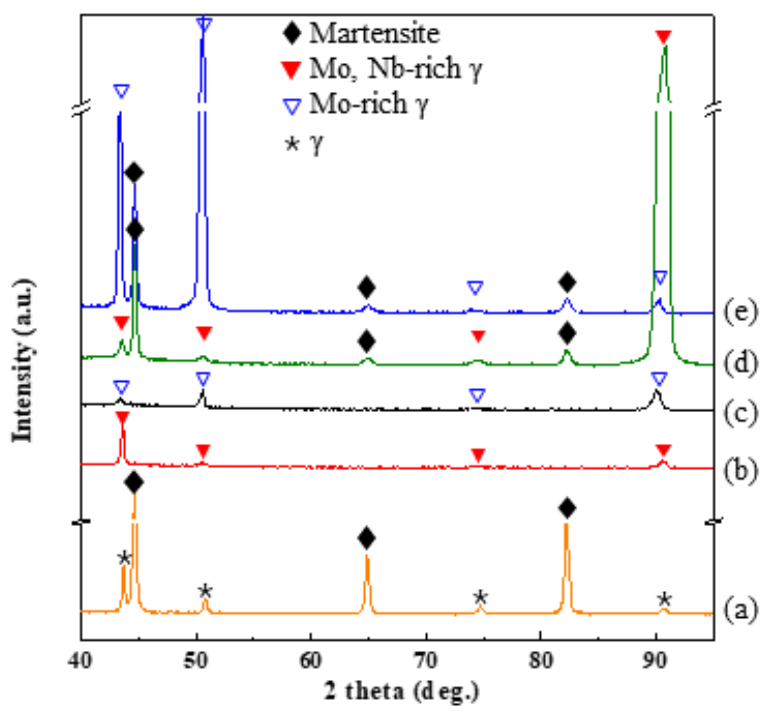

\section{Figure 1}

XRD results of the weld joints from the welding of 9\% Ni steel with Hastelloy 609 and Inconel 625 weld metals; (a) $9 \%$ Ni steel, (b) Inconel 625, (c) Hastelloy 609, (d) weld joint interface with Inconel 625 and base metal, (e) weld joint interface with Hastelloy 609 and base metal
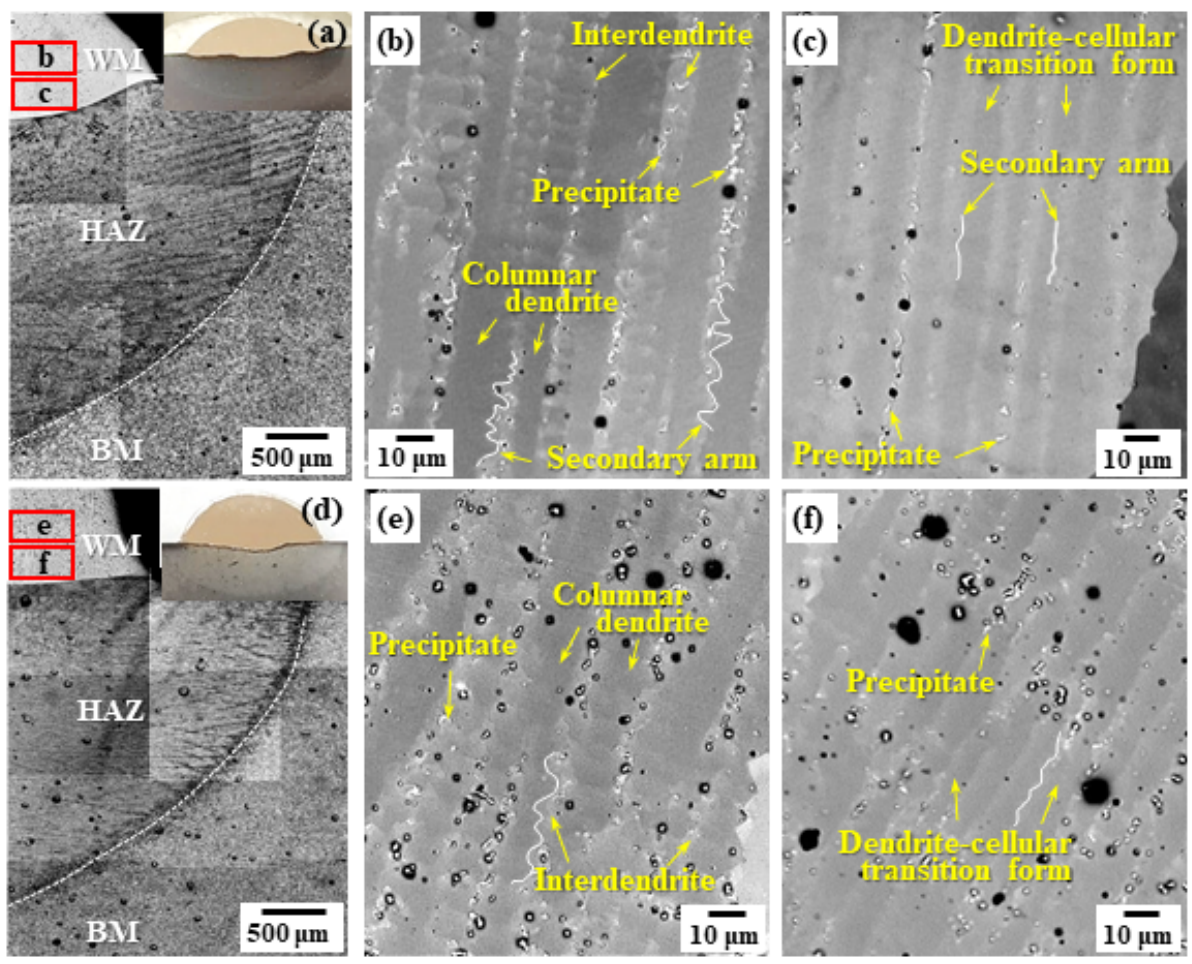

\section{Figure 2}

OM and SEM images of sample welded with (a-c) Hastelloy 609 and $(d-f)$ Inconel 625; (a) cross section of weld joint by Hastelloy 609 , SEM images of (b) center and (c) bottom part of Hastelloy 609 bead, (d) cross section of weld joint by Inconel 625, SEM images of (e) center and (f) bottom part of Inconel 625 bead 

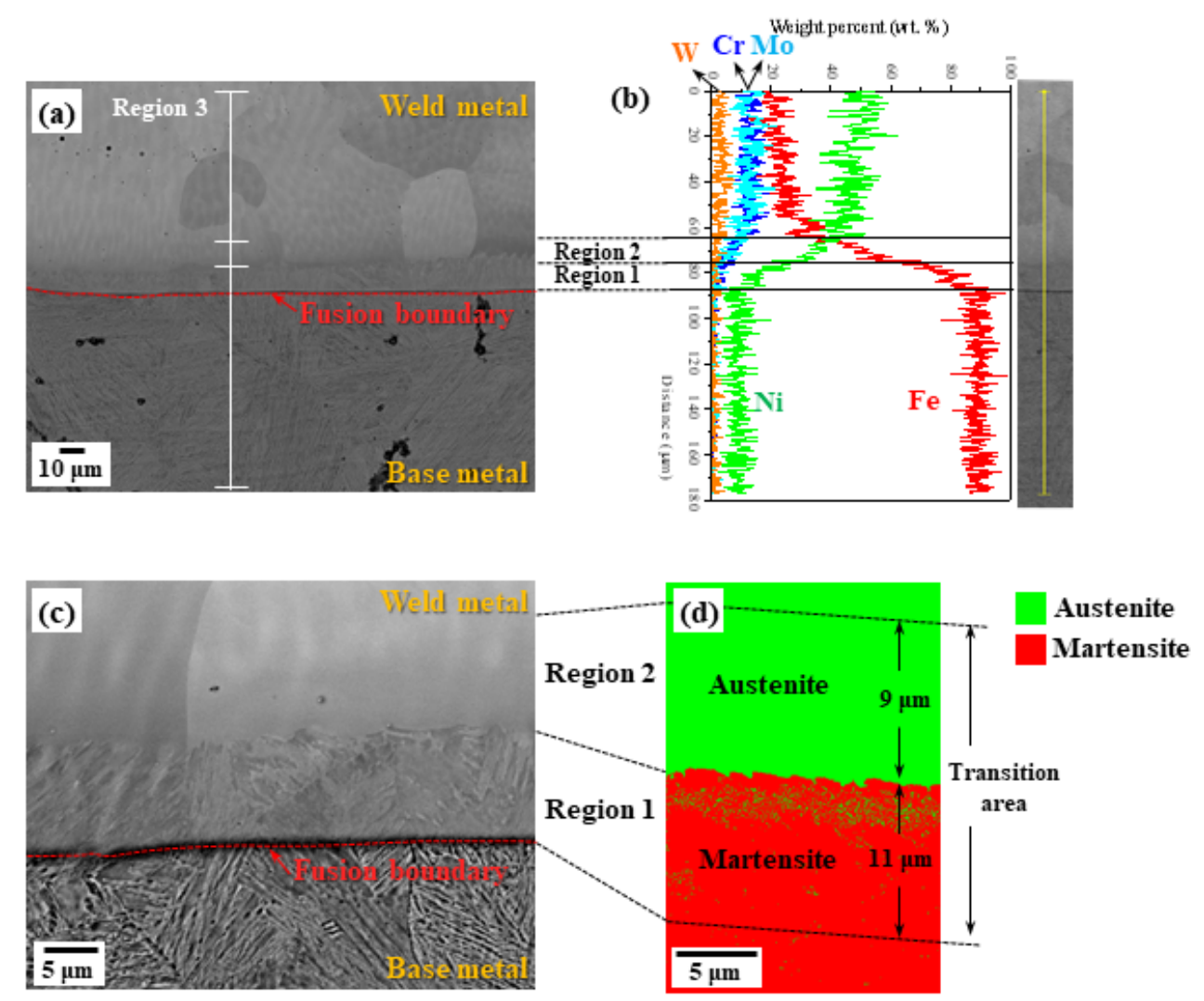

Figure 3

Joint interface welded with Hastelloy 609; (a) SEM image, (b) EDS line analysis, (c) magnified SEM image, (d) EBSD image 

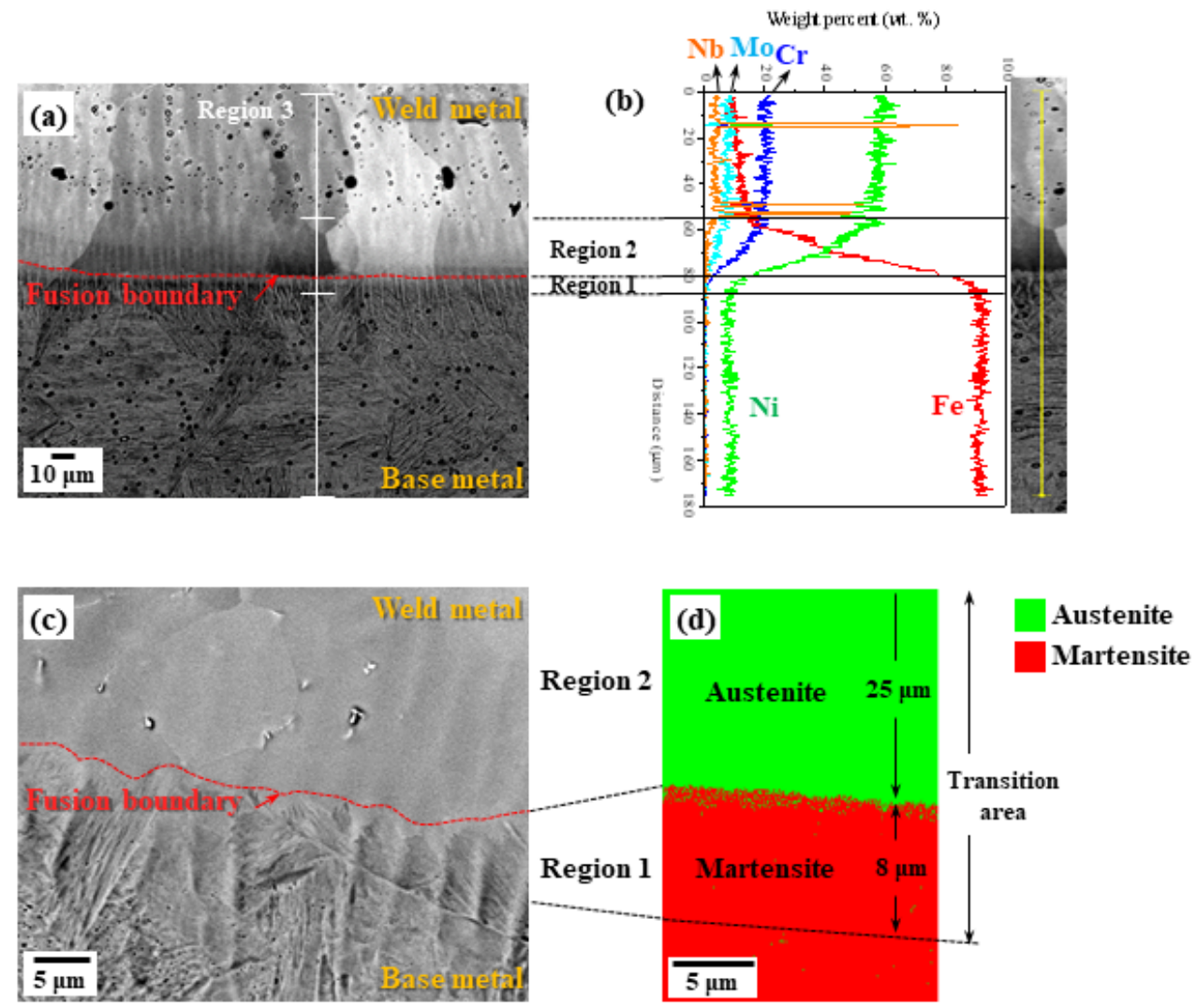

\section{Figure 4}

Joint interface welded with Inconel 625; (a) SEM image, (b) EDS line analysis, (c) magnified SEM image, (d) EBSD image

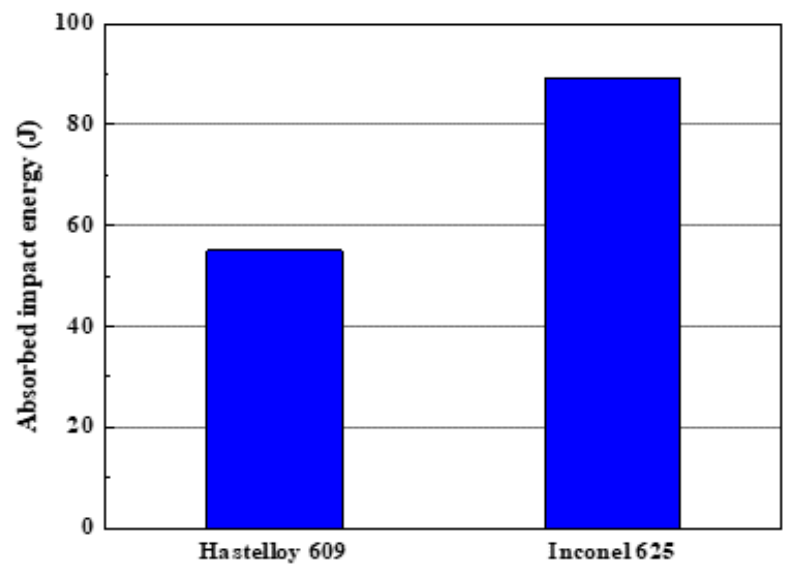

Figure 5

Results of Charpy impact test performed for the weld metal areas in a cryogenic environment at $-196^{\circ} \mathrm{C}$ 

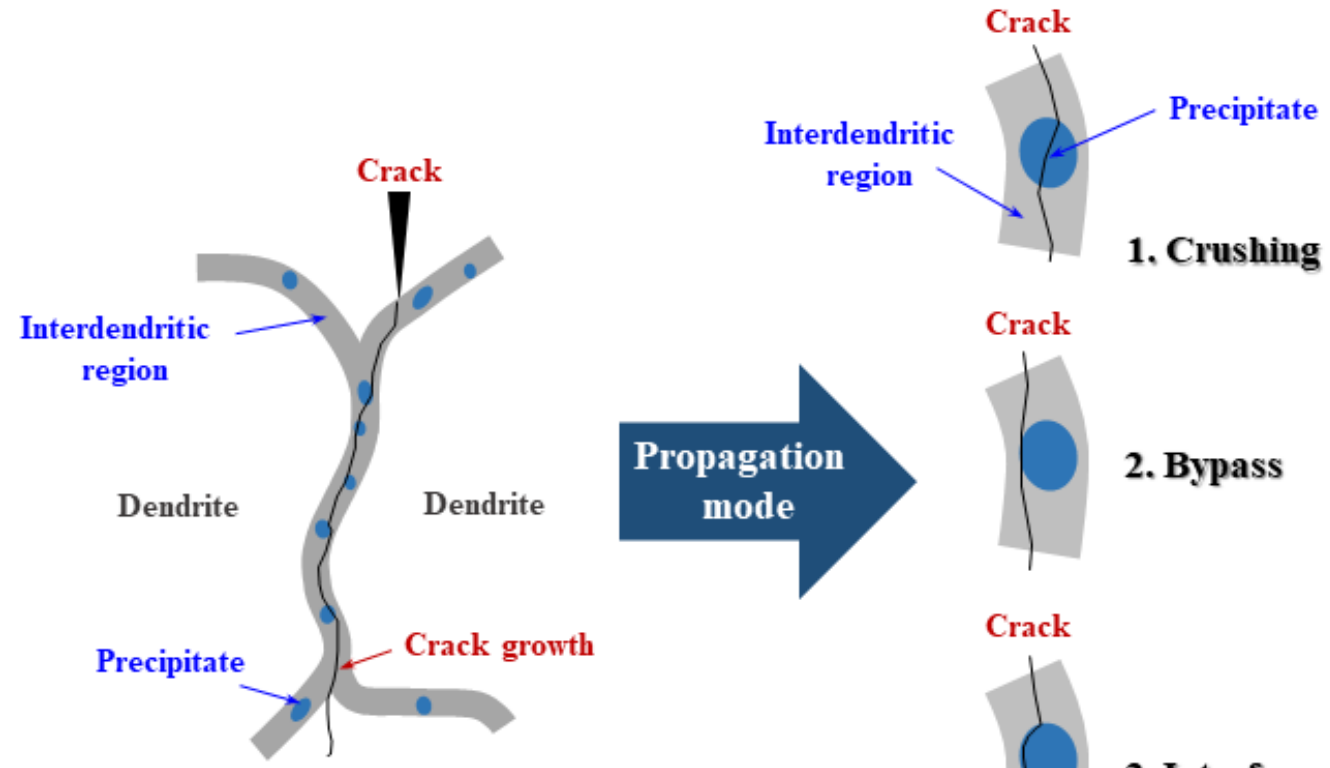

Propagation

mode

Crack
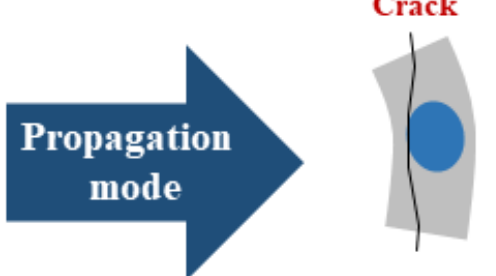

2. Bypass

Crack

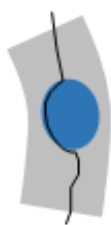

3. Interface

\section{Figure 6}

Schematic diagram of intergranular crack propagation in a cryogenic environment 